case because there was a deficiency rather than an absence of serum IgA.

In seeking for some environmental factor that might explain the discordance for IgA deficiency in these twins the only impressive difference in their early life was the episode of gastroenteritis at six months, which was far more severe in the subsequently healthy twin. Work in germ-free animals ${ }^{11}$ suggests that stimulation by micro-organisms is important in promoting IgA synthesis by the gut. By analogy, the genotype common to these twins might have required a particularly strong stimulus to switch-on IgA synthesis and the episode of gastroenteritis might have occurred at a time critical for the establishment of endogenous IgA production. Whatever the cause of the discordance for IgA deficiency, however, it seems likely that this defect and an associated malabsorption accounted for the slower growth and the childhood illness of one of these twins.

Selective IgA deficiency is sometimes familial, but the reported patterns of familial involvement are variable and the mode of inheritance is not well defined. ${ }^{12}$ Its occurrence in one of identical twins suggests that environmental influence is important in either the initiation or the perpetuation of the deficiency in some people.

We thank Professor Sir Cyril Clarke and Professor C C Booth for their interest and advice. Dermatoglyphic ridge count was performed by the late Professor L S Penrose, tests for red cell isoenzymes and plasma protein polymorphisms at the Galton Laboratory, London Univeristy, and satellite counts on chromosome preparations by Dr F R Engmann.

Requests for reprints should be addressed to Dr R M Lewkonia, Department of Medicine, Hammersmith Hospital, London W 12 OHS.

\section{References}

${ }^{1}$ Crabbé, P A, and Heremans, J F, American fournal of Medicine, 1967, 42, 319.

2 Hobbs, J R, Fournal of Clinical Pathology, 1971, 24, suppl 5, p 146.

${ }^{3}$ Bull, D M, and Tomasi, T B, Gastroenterology, 1968, 54, 313.

4 Smith, S M, and Penrose, L S, Annals of Human Genetics, 1955, 19, 273.

5 Asquith, P, Thompson, R A, and Cooke, W T, Lancet, 1969, 2, 129.

6 Bachmann, R, Scandinavian fournal of Clinical and Laboratory Investigations, 1965, 17, 316.

7 Falchuck, Z M, Rogentine, G N, and Strober, W, fournal of Clinical Investigation, 1972, 51, 1602

${ }^{8}$ Lawton, A W, Kincade, P W, and Cooper, M D, Federation Proceedings, $1975,34,33$.

9 Waldmann, T A, et al, Lancet, 1974, 2, 609.

10 Provisor, A J, et al, New England fournal of Medicine, 1975, 293, 62.

11 Crabbé, P A, et al, International Archives of Allergy, 1968, 34, 363.

12 Grundbacher, F J, fournal of Medical Genetics, 1972, 9, 344.

\title{
Changes in immune status in patients undergoing splenectomy for the staging of Hodgkin's disease
}

\author{
B W HANCOCK, LESLEY BRUCE, A MILFORD WARD, JOHN RICHMOND
}

British Medical fournal, 1976, 1, 313-315

\section{Summary}

The immune status of 17 patients with Hodgkin's disease was studied before and after splenectomy (undertaken in staging laparotomy) and during chemotherapy or after radiotherapy. The findings were compared with those in 19 patients not selected for splenectomy. Serum IgA and IgM levels became significantly lower after treatment in the splenectomy group. Cell-mediated immunity was depressed mainly in patients receiving quadruple cytotoxic chemotherapy. Neutrophil function was normal or enhanced and was unchanged after splenectomy and treatment despite changes in neutrophil counts. Three patients who underwent splenectomy suffered fatal septicaemia. These results suggest that humoral immunity is depressed by treatment in patients who have undergone splenectomy, and the benefits of early accurate staging must be weighed against the likelihood of infective complications.

\footnotetext{
University of Sheffield Academic Division of Medicine, Royal Hospital, Sheffield S1 3SR

B W HANCOCK, DCH, MRCP, lecturer

LESLEY BRUCE, HNC, medical laboratory scientist

JOHN RICHMOND, MD, FRCP, professor

Department of Immunology, University of Sheffield, Sheffield A MILFORD WARD, MB, MRCPATH, senior lecturer
}

\begin{abstract}
Introduction
Diagnostic laparotomy with splenectomy is now a recognised procedure in the staging of Hodgkin's disease. In view of the incidence of severe infections after this operation ${ }^{1}$ we have studied serially the immune status of 17 patients with Hodgkin's disease who underwent splenectomy and compared the findings with those in 19 patients seen over the same period who did not undergo splenectomy. Three patients who died with septicaemia after splenectomy and chemotherapy are discussed more fully.
\end{abstract}

\section{Patients}

It is the policy of the lymphoma group in Sheffield to perform diagnostic laparotomy with splenectomy on patients staged clinically (Ann Arbor) as $1 \mathrm{~A}$ and $2 \mathrm{~A}$ (mixed cellularity or lymphocyte depletion histology types) and 1B, 2B, 3A, (all histology types). In the six months from August 1974 to February 197517 such patients underwent operation. During the same period 19 patients did not require laparotomy before starting treatment.

Seven of the patients who underwent splenectomy and nine of the others were subsequently treated with quadruple cytotoxic chemotherapy; the remainder had radiotherapy apart from one patient in each group who had radiotherapy followed by chemotherapy. Immune status was assessed in all patients at presentation, two to four weeks after splenectomy but before treatment and either immediately after radiotherapy or before the fourth course of quadruple chemotherapy.

There were two deaths in the non-splenectomy group from disemination of Hodgkin's disease. In the splenectomy group four patients died, one from dissemination and three from fulminating septicaemia. The last three patients are reported further.

Case 1-A 50-year-old man with stage $4 \mathrm{~B}$ mixed cellularity Hodgkin's disease received six courses of quadruple chemotherapy before being admitted with Pseudomonas aeruginosa septicaemia, which did not respond 
to broad-spectrum antibiotics. Necropsy confirmed septicaemia. The bone marrow was hypoplastic and there was no evidence of Hodgkin's disease.

Case 2-A 54-year-old woman with stage $3 \mathrm{~A}$ mixed cellularity Hodgkin's disease was initially treated with total modal irradiation followed two months later, when she relapsed, by quadruple chemotherapy. She was admitted after her second course of cytotoxic chemotherapy with Escherichia coli septicaemia resistant to antibiotics. Necropsy confirmed septicaemia. There was no evidence of Hodgkin's disease and the bone marrow was hypoplastic.

Case 3-A 25-year-old man with stage 1A mixed cellularity Hodgkin's disease was treated with mantle irradiation. He responded well and was in remission three months after treatment. $\mathrm{He}$ was then admitted with malaise and died of fulminating meningococcal septicaemia despite early broadspectrum antibiotic and corticosteroid treatment. At necropsy there was no evidence of Hodgkin's disease and the bone marrow was normal.

The immune status of two of these patients (cases 1 and 2) was reassessed during their terminal illness.

\section{Methods}

Differential leucocyte counts were performed at each stage of assessment.

Neutrophil function-Neutrophil function was assessed using the unstimulated nitro-blue tetrazolium test ${ }^{2}$ and by a micro-organism killing test derived from the method of Miles and Misra. ${ }^{3}$ In the latter test a known number of organisms (from cultures of Staphylococcus albus, Diplococcus pneumoniae, and Candida albicans) were incubated with $(a)$ whole blood and $(b)$ separated washed leucocytes. The pathogen kill was calculated by viable counting before and after incubation for one hour at $37^{\circ} \mathrm{C}$. This was corrected for neutrophil count and compared with the kill of a healthy control.

Cellular immunity-Intradermal skin tests were performed with four or five of the following recall antigens: Candida albicans extract 1-100 (Hollister Stiers); mumps antigen (Eli Lilly); old tuberculin 1-1000; streptokinase/streptodornase 50 units (Lederle); trichophyton 1-30 (Hollister Stiers). The test sites were evaluated at 24, 48, and 72 hours, the diameter of any induration being measured. If there was measurable induration of $5 \mathrm{~mm}$ or more in one or more test sites the patient was considered immunocompetent. The leucocyte migration technique used was that described by Søberg and Bendixen ${ }^{4}$ with minor modifications. Separated peripheral leucocytes were allowed to migrate from microcapillary tubes fixed into wells containing (a) control medium, $(b)$ purified protein derivative of tuberculin (PPD), and (c) Candida albicans antigen. The migration area after 20 hours was mapped by projection microscopy and measured by paper planimetry. A migration index was determined by dividing the area of migration with antigen by the area of migration without antigen. Inhibition of migration occurred if this value was 0.8 or less. ${ }^{4}$ Immunocompetence was interpreted as normal if significant inhibition occurred with one or both antigens.

Humoral immunity - Serum immunoglobulins were determined by the automated immunoprecipitin technique.

Statistical significance was assessed from values of probability based on Student's $t$ test.

\section{Results}

The mean neutrophil count $(P<0.05)$ rose significantly after splenectomy and before treatment, but the rise in mean lymphocyte count was barely significant $(P<0 \cdot 1)$ (table I). The mean neutrophil and lymphocyte counts fell significantly after treatment in both splenectomy and non-splenectomy groups $(P<0.05$ and $P<0.01$ respectively), and the fall in mean cell counts was not significantly different between patients in both groups who underwent chemotherapy and those who underwent radiotherapy.

Neutrophil phagocytic function was normal or enhanced in all patients, and there was no significant change after splenectomy. Four

TABLE I-Mean $( \pm S E$ of mean $)$ white cell counts $\left(\times 10^{9} / l\right)$ in both groups

\begin{tabular}{|c|c|c|c|c|c|}
\hline & \multicolumn{2}{|c|}{ Non-splenectomy group } & \multicolumn{3}{|c|}{ Splenectomy group } \\
\hline & Presentation & $\begin{array}{c}\text { After } \\
\text { treatment }\end{array}$ & Presentation & $\begin{array}{c}\text { After } \\
\text { splenectomy }\end{array}$ & $\begin{array}{c}\text { After } \\
\text { treatment }\end{array}$ \\
\hline $\begin{array}{l}\text { Neutrophils } \ldots \\
\text { Lymphocytes .. }\end{array}$ & $\begin{array}{l}6.31+0.81 \\
1.74 \div 0.13\end{array}$ & $\begin{array}{l}4.48 \\
0.99 \\
0.71^{*}\end{array}$ & $\begin{array}{l}5 \cdot 740 \cdot 72 \\
1 \cdot 68+0 \cdot 12\end{array}$ & $\begin{array}{l}8 \cdot 98=1.51 * \\
2 \cdot 25 \div 0.38\end{array}$ & $\begin{array}{l}3 \cdot 88: 0 \cdot 38^{*} \\
1 \cdot 14: 0 \cdot 20^{*}\end{array}$ \\
\hline
\end{tabular}

*Statistically significant change from earlier values $(P<0.02)$.

Conversion: SI to traditional units $-1 \times 10^{9} / 1=1000 \mathrm{~mm}^{3}$.
TABLE II-Results of skin testing and leucocyte migration tests in both groups. Results are numbers (percentages) of patients

\begin{tabular}{|c|c|c|c|c|c|}
\hline & \multicolumn{2}{|c|}{ Non-splenectomy group } & \multicolumn{3}{|c|}{ Splenectomy group } \\
\hline & Presentation & $\begin{array}{c}\text { After } \\
\text { treatment }\end{array}$ & Presentation & $\begin{array}{c}\text { After } \\
\text { splenectomy }\end{array}$ & $\begin{array}{c}\text { After } \\
\text { treatment }\end{array}$ \\
\hline $\begin{array}{l}\text { Immunocompe- } \\
\text { tent patients } \\
\text { Anergic patients }\end{array}$ & $\begin{array}{r}13(68) \\
6(32)\end{array}$ & $\begin{array}{l}\text { Skin test } \\
10(53) \\
9(47)\end{array}$ & $\begin{array}{r}14(82) \\
7(41)\end{array}$ & & $\begin{array}{r}7(41) \\
10(59)\end{array}$ \\
\hline $\begin{array}{l}\text { Immunocompe- } \\
\text { tent patients } \\
\text { Anergic patients }\end{array}$ & $\begin{array}{r}8(42) \\
11(58)\end{array}$ & $\begin{array}{r}6(32) \\
13(68)\end{array}$ & $\begin{array}{l}8(47) \\
9(53)\end{array}$ & $\begin{array}{r}3(18) \\
14(82)\end{array}$ & $\begin{array}{r}7(41) \\
10(59)\end{array}$ \\
\hline
\end{tabular}

patients in each group were assessed after treatment, and no significant change was found.

Skin test immunocompetence was normal in 14 of the 17 patients who underwent splenectomy and 13 of the others at presentation (table II). After treatment only seven in the splenectomy group were immunocompetent whereas 10 in the non-splenectomy group remained competent. With one exception all patients who were immunocompetent at presentation but anergic after treatment received chemotherapy. Leucocyte migration test immunocompetence (table II) showed a transient depression after splenectomy but this was not maintained after treatment.

Mean immunoglobulin levels in the splenectomy group did not change significantly after splenectomy (table III), but after treatment mean IgA and IgM levels fell significantly $(P<0.05$ and $P<0.01$ respectively). Mean IgA also fell in the non-splenectomy group but not significantly. The difference in mean $\operatorname{IgM}$ levels between the groups after treatment was significant $(\mathbf{P}<0.05)$

TABLE III-Mean ( $\pm S E$ of mean) immunoglobulin values $(g / l)$ in both groups

\begin{tabular}{|c|c|c|c|c|c|}
\hline & \multicolumn{2}{|c|}{ Non-splenectomy group } & \multicolumn{3}{|c|}{ Splenectomy group } \\
\hline & $\overline{\text { Presentation }}$ & $\begin{array}{c}\text { After } \\
\text { treatment }\end{array}$ & $\overline{\text { Presentation }}$ & $\begin{array}{c}\text { After } \\
\text { splenectomy }\end{array}$ & $\begin{array}{c}\text { After } \\
\text { treatment }\end{array}$ \\
\hline $\begin{array}{l}\mathrm{IgG} \\
\mathrm{IgA} \\
\mathrm{IgM}\end{array}$ & $\begin{array}{r}11.33 \pm 0.73 \\
2.68 \pm 0.38 \\
1.34: 0.15\end{array}$ & $\begin{array}{r}11.45 \pm 0.86 \\
2.12 \pm 0.21 \\
1.23 \pm 0.14\end{array}$ & $\begin{array}{r}12 \cdot 35 \div 1.09 \\
2 \cdot 86 \pm 0.41 \\
1 \cdot 10=0.19\end{array}$ & $\begin{array}{r}12.23: 0.96 \\
3.00 \div 0.43 \\
0.99: 0.14\end{array}$ & $\begin{array}{c}10 \cdot 68 \pm 0.92 \\
2 \cdot 22 \pm 0 \cdot 22^{*} \\
0.70 \pm 0.12^{* *}\end{array}$ \\
\hline
\end{tabular}

Statistically significant change from earlier values: ${ }^{*} \mathrm{P}<0.05 . \quad{ }^{* *} \mathrm{P}<0.01$.

Assessment of cases 1 and 2 during septicaemia showed considerably impaired cellular immunity (in vivo and in vitro). Leucopenia was evident but neutrophil phagocytosis was enhanced (in case 2). Serum immunoglobulin levels were lower, though within normal ranges, during the septicaemic illness that at the time of presentation with Hodgkin's disease. The third patient was not completely reassessed during septicaemia, but at presentation and after treatment cellular immunity was depressed and serum IgM levels were low. Before death his leucocyte count was raised.

\section{Discussion}

Patients with Hodgkin's disease are at risk from infection for many reasons. Up to $20 \% 5$ have impaired cellular immunity at presentation. They then have radiotherapy or cytoxic chemotherapy, which depresses immunity further. It is therefore important to take these factors into account when looking at the effects of splenectomy. Even though all our patients were selected, we came to some valid conclusions.

Leucocyte counts (raised after splenectomy) were depressed after treatment in both groups, but neutrophil phagocytic function was unimpaired. Lymphopenia may give rise to depressed cellular immunity but this is not always the case. ${ }^{6}$ Certainly the group of patients who showed most $\mathrm{T}$-cell depression (as judged by skin testing) were those who received chemotherapy, and the mean lymphocyte count in this group was not significantly different from that of the patients who received radiotherapy.

In-vitro testing suggested that temporary impairment of cellular immunity followed splenectomy. There was no apparent 
fall-off, however, when the tests were repeated after treatment. The difference between results obtained from in-vivo and invitro testing of cellular immunity requires further investigation. In the patients who underwent splenectomy mean serum IgA and IgM levels were significantly depressed after treatment (but not immediately after splenectomy) compared with pretreatment levels. No such change was seen in the other patients after they had been treated. Immunoparesis involving IgM is a contributory factor in the genesis of septicaemia and the spleen is thought to be a major site of IgM synthesis. '

The two patients who died with Gram-negative septicaemia showed considerable depression of cellular immunity during their terminal illness; leucocyte counts were low as a result of cytotoxic myelodepression, but neutrophil phagocytosis and killing was enhanced (in case 2). Immunoglobulin levels were normal but were lower than at presentation. Levels of $\operatorname{IgM}$ were inappropriately low in response to fulminating septicaemia. In case 3 depressed serum IgM levels and cellular immunity were noted after treatment.

The importance of radiotherapy or chemotherapy, or both, in depressing immunity in patients with Hodgkin's disease who have undergone splenectomy is shown by the patient described by Ammann. ${ }^{8}$ This 14 -year-old boy received radiotherapy and chemotherapy after splenectomy. He then developed pneumococcal meningitis. After recovery he was immunised with pneumococcal polysaccharides and was unable to respond with antibody formation. Children who have had splenectomy for reasons other than Hodgkin's disease responded normally to immunisation. Ammann ${ }^{8}$ suggested that radiotherapy and chemotherapy depress the macrophage processing of antigen and antibody or cellular immunity, or both.

Splenectomy is valuable in staging and managing Hodgkin's disease, but there is evidence that IgA and IgM levels are depressed, and three out of our 17 patients died of septicaemia. More information is required on the morbidity and infective complications of splenectomy so that these may be balanced against the benefits of better initial staging of the patient's disease.

We thank the department of medical microbiology, academic division of pathology, and, particularly, $\mathrm{Mr} \mathrm{B} M$ Jones for microbiological facilities; Drs I G Emmanuel, F E Neal, G $M$ King, P Huck, and J Walter of Weston Park Hospital, whose patients we studied; and the Cancer Research Campaign (Yorkshire Branch) for financial assistance.

\section{References}

${ }^{1}$ Desser, R K, and Ultman, J E, Annals of Internal Medicine, 1972, 77, 143. 2 Park, B H, Fikrig, S M, and Smithwick, E M, Lancet, 1968, 2, 532.

Miles A A, and Misra, S S, fournal of Hygiene, 1938, 38, 732.

S Sberg, M, and Bendixen, G, Acta Medica Scandinavica, 1967, 181, 247.

5 Hancock, B W, unpublished work.

'Steihm, E R, et al, Annals of Internal Medicine, 1972, 77, 101.

i Schumacher, M J, Archives of Disease in Childhood, 1970, 45, 114.

Ammann, A J, Annals of Internal Medicine, 1973, 78, 151.

\title{
Sterculia bulk-forming agent with smooth-muscle relaxant versus bran in diverticular disease
}

\author{
G S SRIVASTAVA, A N SMITH, N S PAINTER
}

\section{Introduction}

Colonic diverticula are caused by high pressures produced by the segmenting action of the colonic muscle. Segmentation not only propels the colon's contents but halts material moving through the lumen. ${ }^{1-3}$ Cineradiography combined with pressure recording shows that natural stimulation or stimulation by drugs produces in the diseased sigmoid an excessive number of waves of high intracolonic pressure. These high pressures favour the progression of established diverticulosis and are almost certainly responsible for the initial herniation of the colonic mucosa. Extreme degrees of segmentation may cause intermittent occlusion of the lumen of the sigmoid and recurrent functional obstruction, which result in episodes of abdominal pain. In about two-thirds of patients this pain is not due to inflammatory diverticulitis, ${ }^{4}$ and most clinicians believe that the colic of painful diverticular disease is caused by strong contractions of the colonic muscle. ${ }^{5}$ Contractions of the colon have been correlated with episodes of severe abdominal pain in the "irritable bowel syndrome." "Hence the behaviour of the colonic muscle probably plays an important part in the genesis of diverticular disease and other colonic disorders.

The intraluminal pressure may be reduced in diverticular disease by adding cereal fibre to the diet in the form of millers' bran, ${ }^{7}$ particularly when the fibre is coarsely ground. ${ }^{8}$ Not all patients, however, tolerate bran, and as the bulk-forming agent sterculia (Normacol) has been shown to relieve the symptoms of diverticular disease ${ }^{9}$ we decided to test two preparations of sterculia-one of sterculia alone and one containing a smoothmuscle relaxant-to see what effect they would have on intra-

\author{
Wolfson Gastro-Intestinal Laboratories, Western General Hospital, \\ S SRIVASTAVA, BSC, MS, Lieutenant-Colonel, Indian Army, train \\ Hospital, Delhi Cantt, India) \\ University Department of Clinical Surgery, Western General \\ Hospital, Edinburgh EH4 2 XU \\ A N SMITH, MD, FRCSED, reader in clinical surgery \\ Manor House Hospital, London NW11 7 HX \\ N S PAINTER, FRCS, FACS, senior surgeon \\ Sterculia with and without a smooth-muscle relaxant \\ (alverine citrate) had similar beneficial effects on con- \\ sterculia plus alverine citrate than to those of sterculia \\ S PAINTER, FRCS, FACS, senior surgeon
}

